\title{
First report of box blight caused by Cylindrocladium buxicola in Georgia
}

\author{
L. Gorgiladze ${ }^{1}$, G. Meparishvili ${ }^{1}$, Z. Sikharulidze ${ }^{1 *}$, K. Natsarishvili $^{1}$ and R. Davitadze ${ }^{2}$ \\ ${ }^{1}$ Institute of Phytopathology of Georgia, 6200, Kobuleti, Georgia; ${ }^{2}$ Mtirala National Park, Kobuleti, v.Chakvi, Georgia \\ *E-mail: zoia_sikharulidze@yahoo.com
}

Received: 18 Jan 2011. Published: 28 Apr 2011. Keywords: Buxus colchica, pathogen, fungus, conidia

Buxus colchica is a relict species of box of the Black Sea coast of Georgia. The main growing area of B. colchica is located in the Mtirala National Park (Kobuleti region, Ajara, Western Georgia). In November 2010, symptoms of dark brown spots on leaves, narrow blackish streaks on the stems and defoliation were observed on box plants (B. colchica). Severe blight symptoms were found on $70 \%$ of the box plants in this locality (Fig. 1). The symptoms we observed were similar to box blight, caused by Cylindrocladium buxicola, reported in Croatia, Spain, Italy, Germany, Belgium and the United Kingdom (Henricot et al., 2000; Brand, 2005; Crepel \& Inghelbrecht, 2003; Saracchi et al., 2008; Pintos et al., 2009; Cech et al., 2010).

To induce sporulation, diseased leaves and stem pieces were incubated in a moist chamber at $22^{\circ} \mathrm{C}$. After five days of incubation, the fruiting bodies of the fungus developed (Fig. 2). Conidiophores growing on the surface of the box leaves and stem parts were examined under the microscope. Cylindrical, hyaline conidia, 52-65 x 4-6 $\mu \mathrm{m}$ in size, rounded at both ends, with one septum were observed. Conidia were produced on conidiophores with penicillate arrangement. Conidia were transferred onto potato dextrose agar medium. Colonies grew slowly and after two weeks incubation at $24^{\circ} \mathrm{C}$ reached $3.5 \mathrm{~cm}$ in diameter. The colony reverse was brown in the centre surrounded by a creamy mycelial growth. The colony surface was covered by aerial cottony mycelium (Fig. 3). Pathogenicity tests were conducted onfour-year-old plants of B. colchica. Whole plants were inoculated by spraying a spore suspension of the fungus (1x10 conidia/ml). Inoculated plants were incubated at $25^{\circ} \mathrm{C}$ and $100 \%$ humidity in a moist chamber in the laboratory. Some plants were sprayed with sterile water as a control. Three days after inoculation, the first lesions appeared. All inoculated plants showed blight symptoms on leaves and stems within two weeks, which were identical to those previously described (Fig. 4). Control plants remained unaffected.The pathogen was re-isolated from lesions thereby completing Koch's postulates. Based on the morphological and cultural characters, the pathogen isolated from $B$. colchica wasidentified as Cylindrocladium buxicola.To our knowledge, this is the first report on the presence of $C$. buxicola on $B$. colchica in Georgia.

\section{Acknowledgements}

This study was conducted under ISTC partner project \# G-1775. We thank Richard Thwaites for his assistance.

\section{References}

Brand T, 2005. Outbreak of Cylindrocladium buxicola B. Henricot on boxwood in Northwest-Germany. Nordwest-Deutschland.

Nachrichtenblatt des Deutschen Pflanzenschutzdienstes 57, 237-240.

Cech T, Diminic D, Heungens K, 2010. Cylindrocladium buxicola causes common box blight in Croatia. New Disease Reports 22, 9.

[doi:10.1111/j.1365-3059.2010.02361.x]

Crepel C, Inghelbrecht S, 2003. First report of blight on Buxus spp. caused by Cylindrocladium buxicola in Belgium. Plant Disease 87, 1539.

[doi:10.1094/PDIS.2003.87.12.1539A]

Henricot B, Pérez Sierra A, Prior C, 2000. A new blight disease on Buxus in the UK caused by the fungus Cylindrocladium. Plant Pathology 49, 805. [doi:10.1046/j.1365-3059.2000.00508.x]

Pintos Varela C, Gonzáles Penalta B, Mansilla Vázquez JP, Aguin Casal O, 2009. First report of Cylindrocladium buxicola on Buxus sempervirens in Spain. Plant Disease 93, 670. [doi:10.1094/PDIS-93-6-0670B]

Saracchi M, Rocchi F, Pizzatti C, Cortesi P, 2008. Box blight, a new disease of Buxus in Italy caused by Cylindrocladium buxicola. Journal of Plant Pathology 90, 581-583.

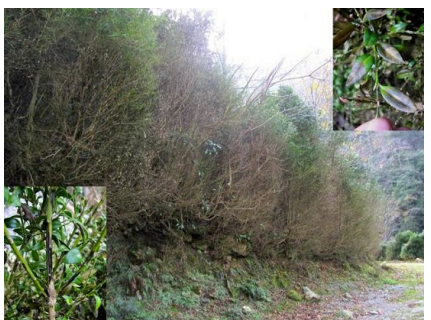

Figure 1
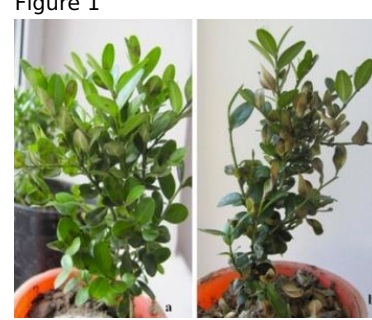

Figure 2

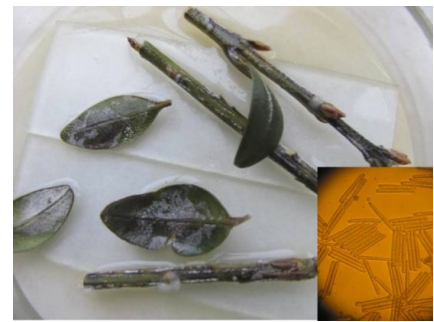

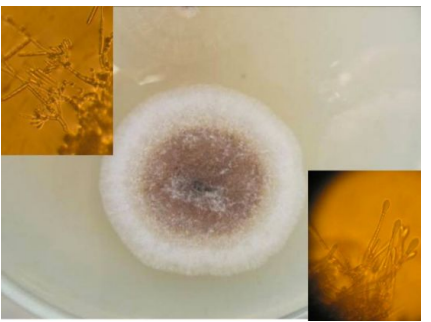

Figure 3

Figure 4

To cite this report: Gorgiladze L, Meparishvili G, Sikharulidze Z, K.Natsarishvili, Davitadze R, 2011. First report of box blight caused by Cylindrocladium buxicola in Georgia. New Disease Reports 23, 24. [doi:10.5197/j.2044-0588.2011.023.024]

(c) 2011 The Authors

This report was published on-line at www.ndrs.org.uk where high quality versions of the figures can be found. 